\title{
PENERAPAN KONSEP PENGHAWAAN ALAMI PADA DESAIN SANATORIUM DI KABUPATEN GOWA
}

\author{
Suhardi $M^{* 1}$, Marwati2 ${ }^{2}$ Nursyam ${ }^{3}$ \\ Jurusan Teknik Arsitektur, Universitas Islam Negeri Alauddin Makassar ${ }^{1}$ \\ Jurusan Teknik Arsitektur, Universitas Islam Negeri Alauddin Makassar ${ }^{2}$ \\ Jurusan Teknik Arsitektur, Universitas Islam Negeri Alauddin Makassar ${ }^{3}$ \\ e-mail: ${ }^{* 1}$ suhardijong@gmail.com, ${ }^{2}$ marwati.adalle@uin-alauddin.ac.id, \\ ${ }^{3}$ nursyam.abidah@gmail.com
}

\begin{abstract}
Abstrak_Salah satu prinsip arsitektur berkelanjutan berupa sistem penggunaan energi yang efisien seperti penghawaan yang alam dan kurangnya fasilitas rehabilitasi di Kabupaten Gowa. Sanatorium adalah wadah dengan basis pelaksanaan tindakan medis yang berfungsi sebagai tempat isolasi, perawatan dan rehabilitasi pasien TBC (Tuberculosis). Tujuan penulisan adalah membuat desain sanatorium dengan menggunakan konsep penghawaan alami yang berlokasi di Kabupaten Gowa, Kecamatan Pattallassang, Desa Timbuseng. Metode pembahasan diawali dengan pengumpulan data yang diolah melalui analisis dan sintesis data yang kemudian diproses menjadi sebuah konsep perancangan sanatorium meliputi kondisi fisik lokasi, bentuk dan ruang, letak dan bentuk bukaan jendela. Proses analisis diawali dengan pembahasan kondisi fisik tapak berupa elevasi tanah, orientasi angin, lintasan matahari, suhu pada tapak. Kemudian dilanjutkan dengan pengolahan zona ruang dan bentuk dan diakhiri dengan pembahasan letak bukaan jendela pada bangunan. Hasil desain meliputi letak bangunan yang bermassa yang dipisah ruang terbuka, bentuk bangunan tidak lebar, pengelompokan ruang yaitu zona perawatan, pengelola, poliklinik dan konsep penerapan penghawaan alami berupa model bukaan jendela terbuka pada zoning perawatan
\end{abstract}

Kata Kunci: Penghawaan Alami; Sanatorium; Kabupaten Gowa .

\begin{abstract}
One of the principles of sustainable architecture in the form of efficient energy use systems is natural memorization and lack of rehabilitation facilities in the Gowa district. The Sanatorium is a container with an implementation base of preventive action that serves as a place of isolation, maintenance, and rehabilitation of TB patients (Tuberculosis). The purpose of writing is to create a sanatorium design using an original memorizing concept in Gowa District, Pattallassang subdistrict, Timbuseng village. The discussion method begins with the collection of data processed through the analysis and synthesis of data then transformed into a design concept of the Sanatorium covering the physical condition of the location, shape, and space, layout and shape of the window openings. The analysis process begins with discussing the site's physical health in the land elevation, wind orientation, sun trajectory, and tread temperature. Then it is followed by the processing of space zones and shapes and concludes with the discussion of window openings in buildings. The results of the design include a building that has a mass split open space, the form of the building is not comprehensive, the space grouping is the maintenance zone, the organizer, the Polyclinic and the concept of implementation of natural aspiration in the form of the open window opening in the treatment zoning
\end{abstract}

Keywords: Natural Conditioning, Sanatorium, Gowa Districts

\footnotetext{
${ }^{1}$ Jurusan Teknik Arsitektur, Universitas Islam Negeri Alauddin Makassar

2 Jurusan Teknik Arsitektur, Universitas Islam Negeri Alauddin Makassar

3 Jurusan Teknik Arsitektur, Universitas Islam Negeri Alauddin Makassar
} 


\section{PENDAHULUAN}

Tuberculosis (TBC) masih menjadi salah satu jenis penyakit menular yang membunuh ribuan orang setiap tahunnya. Menurut data World Health Organizantion (WHO) pada tahun 2016 diperkirakan jumlah penderita TBC aktif mencapai angka 9,6 juta. Indonesia sebagai salah satu negara dengan jumlah penduduk terbanyak di dunia berada di urutan kedua pasien penderita aktif TBC setelah India. Hal ini dapat meningkat secara signifikan setiap tahunnya karena penanganan dan protokol pelaksanaan perawatan yang belum memadai serta kesadaran dari penderita untuk melakukan tidak kontak langsung dengan keluarga bahkan orang di sekitarnya (Warren 2016). Sanatorium sebagai salah satu wadah untuk merawat pasien TBC menjadi alternatif untuk menekan jumlah penderita penyakit yang menyerang sistem pernapasan ini. Pada tahun 1854 di mana wadah ini pertama kali diperkenalkan oleh seorang dokter kebangsaan Jerman bernama Hermann Behmeer terbukti efektif menurunkan jumlah pasien TBC dengan metode diet yang sehat dan penanganan yang tepat. Sanatorium tidak hanya dijadikan sebagai wadah penanganan pasien namun juga berfungsi sebagai lokasi isolasi yang tepat sehingga bakteri TBC yang menular melalui udara tidak dapat menginfeksi orang di sekitarnya (Budiastuti, Mauliani, dan Nuraini, 2018.).

Kegiatan penanganan dalam Sanatorium meliputi kegiatan merawat dan dirawat seperti rumah sakit pada umumnya. Namun pada sistem diet sehat yang diterapkan mengharuskan perancang untuk menyediakan ruang isolasi per individu sehingga perawatan dapat dilakukan secara maksimal, pengadaan fasilitas ruang penunjang seperti ruang berjemur dan bersantai, serta pendukung yang lain seperti taman-taman dan plaza selama masa perawatan. Sebagai salah satu negara dengan jumlah penderita TBC terbanyak di dunia, Sanatorium di Indonesia tidak difungsikan sebagaimana mestinya. Sanatorium di Indonesia telah lama tidak difungsikan, beberapa menjadi rumah sakit lainnya. Tidak ada kabar pasti pandemi ini berakhir meskipun telah ditemukan vaksin untuk mencegah terjadinya penyakit ini, namun berdasarkan data yang ada, jumlah pasien TBC di Indonesia meningkat setiap tahunnya. Pengembalian dan pembangunan fasilitas Sanatorium menjadi langkah tepat untuk mengurangi pasien secara masif dan terorganisir. Dengan demikian diharapkan fungsi sanatorium sebagai wadah isolasi dan penanganan pasien TBC dapat difungsikan kembali (Kompas.com).

Perancangan sebuah gedung sejenis fasilitas kesehatan tidak serta merta langsung dilaksanakan tanpa memperhatikan kondisi lingkungan sekitar. Beberapa pertimbangan harus dipenuhi dalam perancangan seperti halnya iklim, kondisi geografis, pengolahan limbah serta dampak dari pembangunan terhadap masyarakat sekitar secara langsung sehingga diharapkan bangunan ini menjadi wadah yang tepat dan memiliki tingkat kenyamanan yang optimal untuk pengguna di dalamnya. Pendekatan konsep arsitektur berkelanjutan masih menjadi topik yang hangat untuk dibahas dan diterapkan dalam bangunan. Dengan beberapa unsur yang ada di dalamnya, diharapkan dalam penggunaan bangunannya dapat menjadi solusi bangunan yang ramah lingkungan, hemat energi dan pengolahan material yang tepat. dalam perancangan Sanatorium ini hendaknya memperhatikan keselarasan dan kemudahan pengguna di dalamnya, sehingga konsep berkelanjutan pada bangunan menggunakan konsep penghawaan alamiah. (Ardiani 2015).

Penekanan konsep penghawaan alami sejalan dengan salah satu metode perawatan pasien TBC yang tidak memperbolehkan setiap pasien terpapar penghawaan buatan seperti AC dan kipas angin. Dalam beberapa hal memang diperlukan, namun secara signifikan untuk mempercepat proses penyembuhan diharapkan tidak menggunakan fasilitas tersebut. Meskipun telah 
ditemukan alternatif-alternatif penghawaan yang tepat, diharapkan dengan pengurangan penggunaan penghawan buatan secara masif dapat membantu mengurangi konsumsi energi listrik di dalam bangunan, sehingga dapat menjadi solusi penghematan energi yang berkelanjutan. kinerja bukaan jendela dapat meningkatkan kecepatan angin serta perluasan persebaran angin dalam ruang dengan mengganti tipe bukaan menjadi jendela geser vertical dan jendela nako dan menambah dimensi bukaan menjadi 21\%. Penggunaan tipe bukaan jendela inlet dengan tipe jendela geser vertical dan bukaan jendela outlet dengan tipe nako (Jalousie) serta penggunaan nako pada ventilasi dapat mengalirkan angin secara optimal (Arifah dan Adhitama 2017). Berdasarkan standar yang telah ditetapkan SNI Departemen Umum, sebuah ruang pada rumah tinggal harus memiliki ventilasi tidak kurang dari 5\% dari luas lantai ruangan dan jendela 10\% dari luas lantai ruangan. Bukaan bangunan sangat berpengaruh terhadap upaya pemanfaatan angin dalam pengkondisian ruangan. Ukuran bukaan dapat disesuaikan dengan kebutuhan aliran angin.Kecepatan angin yang memasuki ruangan dipengaruhi oleh perbandingan luas inlet dan outlet. Ketika inlet lebih besar dari pada outlet, maka kecepatan udara di dalam ruangan akan lebih rendah dari pada di luar. Ketika inlet lebih kecil dari outlet, maka kecepatan udara di dalam ruangan akan lebih tinggi dari pada di luar (SNI 2001). Bukaan jendela dengan tipe jendela gantung serta ventilasi yang dimiliki oleh ruang kelas dan asrama memiliki kinerja yang kurang optimal serta belum memenuhi standar.

Hal ini dapat dilihat dari luas bukaan jendela dan bukaan ventilasi yang kurang memenuhi standar sehingga pergerakan udara di dalam ruangan tidak dapat dimaksimalkan. Setelah dilakukan proses simulasi rekomendasi dengan mengganti tipe bukaan inlet dan outlet serta mengubah dimensi bukaan didapatkan hasil pegingkatan kinerja serta menyeimbangkan kondisi temperatur udara dalam ruangan agar kenyamanan termal tetap terjaga (Utomo and Iyati 2019). Pusat rehabilitasi ini mendukung konsep healing environment yang pada dasarnya bertujuan untuk mempercepat proses penyembuhan dengan cara merangsang kondisi pasien baik secara psikologis maupun emosional dan memberikan pelayanan kesehatan bagi pasien penderita (Kusumawardani dan Thojib 2015). Dengan demikian perlunya menerapkan konsep penghawaan alami pada fungsi bangunan sanatorium sebagai fungsi rehabilitasi pasien TBC di Kabupaten Gowa.

\section{METODE}

Metode pembahasan diawali dengan pengumpulan data yang diolah melalui analisis dan sintesis data yang kemudian diproses menjadi sebuah konsep perancangan. Pengumpulan data primer dilakukan dengan metode deskriptif kualitatif dengan menjelaskan latar belakang kebutuhan fungsi Sanatorium, identifikasi kondisi tapak yang menjadi lokasi perancangan dan standar kenyamanan penghawaan alami. Sedangkan pengumpulan data sekunder diperoleh dari pembelajaran pustaka terkait fungsi sanatorium dan konsep penghawaan alami. Tahap analisis dan sintesis dimulai dengan mengolah data secara sistematis dan menerapkan metode desain seperti metode pragmatis, tipologi dan metafora yang disesuaikan dengan variabel kondisi fisik lokasi, bentuk dan ruang, letak dan bentuk bukaan jendela. Konsep perancangan yang telah didapat lalu ditransformasikan ke dalam bentuk grafis dengan menggunakan metode ekplorasi desain sehingga dapat memperoleh gambar perancangan yang menerapkan konsep bukaan pengawaan alami dalam desain sanatorium di Kabupaten Gowa. 


\section{HASIL DAN PEMBAHASAN}

\section{A. Konsep Lokasi}

Dalam mengolah konsep lokasi desain sanatorium dengan konsep penghawaan alami yang berada pada Kabupaten Gowa, Kecamatan Pattalassang, Desa Timbuseng dilakukan beberapa pertimbangan yaitu; elevasi, view, lintasan matahari, dan iklim.

\section{Elevasi}

Kondisi elevasi tanah dalam hal ini adalah tingkat kontur suatu kawasan yang layak untuk dijadikan lahan perancangan. Hal ini berkaitan dengan keselamatan moda transportasi dan ketercapaian suatu objek. Semakin landai suatu elevasi tanah, maka semakin optimal perancangan suatu bangunan. Tidak terkecuali untuk bangunan dengan fasilitas kesehatan. Lokasi yang memiliki nilai ideal untuk pembangunan fasilitas kesehatan adalah kecamatan Somba Opu, Pattallassang, Pallangga, Bontonompo Selatan, Bontonompo, Bontomarannu, Barombong, Bajeng Barat, dan Bajeng (tabel 1). Hal ini mengindikasikan bahwa kecamatan tersebut berada di dataran rendah dengan kontur tanah yang cukup landai dan layak untuk dijadikan lokasi bangunan sanatorium.

Tabel 1. Data Elevasi Kabupaten Gowa

\begin{tabular}{llc}
\hline No. & \multicolumn{1}{c}{ Nama Kecamatan } & Elevasi \\
\hline 1. & Somba Opu & 30.9 \\
\hline 2. & Pattallassang & $\mathbf{2 9}$ \\
\hline 4. & Bontomarannu & 30.9
\end{tabular}

Sumber: Data BPS (2017)

Analisis elevasi tapak bertujuan untuk mengetahui tinggi rendahnya permukaan tanah yang terdapat di dalam tapak. Hal ini tentu berkaitan dengan aspek-aspek arsitektur yang ada di dalamnya, seperti bentuk bangunan, jumlah lantai dan perletakan ruang di dalamnya. Berikut ini analisis elevasi tanah yang terdapat dalam tapak.

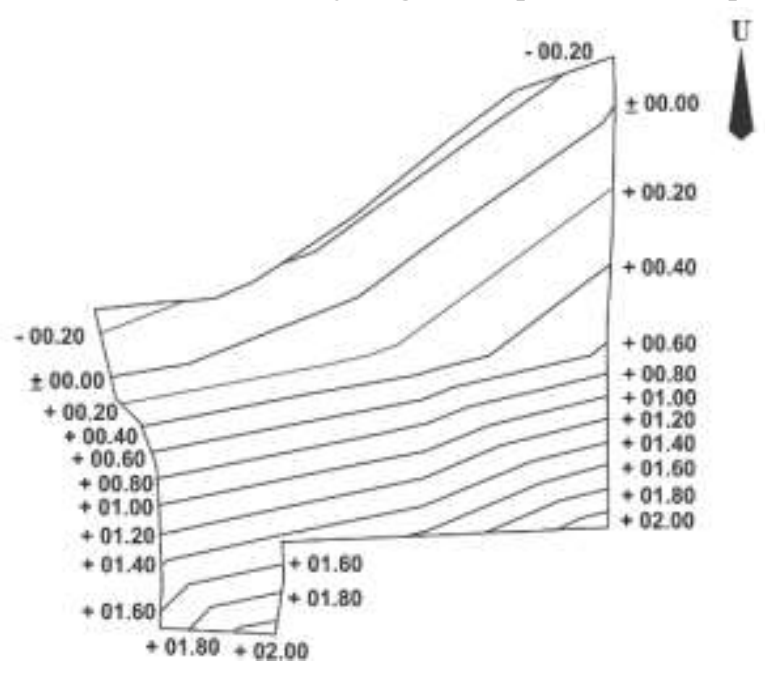

Gambar 1. Analisis Elevasi Tapak Sumber: Olah Data, 2019 
Pada lokasi perancangan, elevasi tanah terlihat cukup rata pada keempat sisi bangunan. Hal ini memudahkan dalam mengelola bangunan di dalamnya. Untuk daerah yang memiliki ketinggian dan lubang seluas tidak lebih dari $2 \mathrm{~m}$, maka akan ditutup dengan tanah. Hal yang perlu dipertimbangkan dalam pengolahan tapak adalah sirkulasi dan penempatan fungsi bangunan.

\section{Temperature Tahunan Lokasi}

Perancangan sebuah sanatorium harus memperhatikan tingkat kenyamanan suhu ruang yang berada pada suhu kondisi yang nyaman adalah suhu $20.8^{\circ} \mathrm{C}-27.1^{\circ} \mathrm{C}$ (Kementerian Kesehatan RI, 2018). Berikut ini data temperatur beberapa lokasi yang optimal di kabupaten Gowa.

Tabel 2. Data Temperatur suhu kabupaten Gowa

\begin{tabular}{llcc}
\hline \multirow{2}{*}{ No. } & \multicolumn{2}{c}{ Nama Kecamatan } & \multicolumn{2}{c}{ Musim } \\
\cline { 3 - 4 } & & Hujan (derajat celcius) & Kemarau (derajat celcius) \\
\hline 1. & Somba Opu & 30.9 & 31.1 \\
\hline 2. & Pattallassang & $\mathbf{2 9}$ & $\mathbf{3 0 . 1}$ \\
\hline 4. & Bontomarannu & 30.9 & 29.9 \\
\hline
\end{tabular}

Sumber: (Data BPS, 2017)

Indeks kualitas udara untuk daerah kabupaten Gowa dan sekitarnya 51 mencapai poin 70 dengan indeks standar lingkungan hidup adalah 60 (Tribun Timur 2016). Namun dalam hal perancangan sebuah fasilitas kesehatan harus memperhatikan tingkat kenyamanan suhu. Kenyamanan termal akan berpengaruh terhadap tingkat penyembuhan dan rasa betah yang dialami oleh pasien yang sedang dirawat

Dengan demikian dapat didapatkan kesimpulan bahwa kecamatan Pattallassang (Tabel 2) menjadi salah satu lokasi yang layak untuk pembangunan Sanatorium. Karakteristik kecamatan Pattallassang terdiri dari dataran tinggi dan dataran rendah. Dataran rendah berada di desa Sunggumanai, Pattallassang, Paccellekang, Panaikang, Moncongloe, dan Pallantikang. Sedangkan untuk daerah dataran tinggi berada di daerah Bollangi, Timbuseng dan Teamate. Untuk daerah dengan kondisi udara yang relatif segar berada di daerah dataran tinggi namun tidak mencapai ketinggian gunung. Desa Timbuseng memiliki karakteristik daerah dataran tinggi dan pepohonan yang masih rindang beserta fasilitas lain yang memadai.

Berdasarkan data dan survei lapangan, dapat dilihat bahwa kondisi terkini tapak mempunyai kontur yang berbeda dari ketinggian jalan utama dengan kondisi tanah yang cukup rata dan ditumbuhi oleh rumput dan ilalang yang lebat. Beberapa titik ditumbuhi oleh pohon yang ketinggiannya mencapai lebih dari 3 meter. Sistem utilitas di lokasi belum didukung oleh drainase yang jelas tetapi diarahkan pada jalur kali yang digunakan oleh bangunan di sekitarnya serta air berasal dari sumber mata air pegunungan dan pada musim kemarau bangunan setempat mengandalkan sumur bor (gambar 2). 

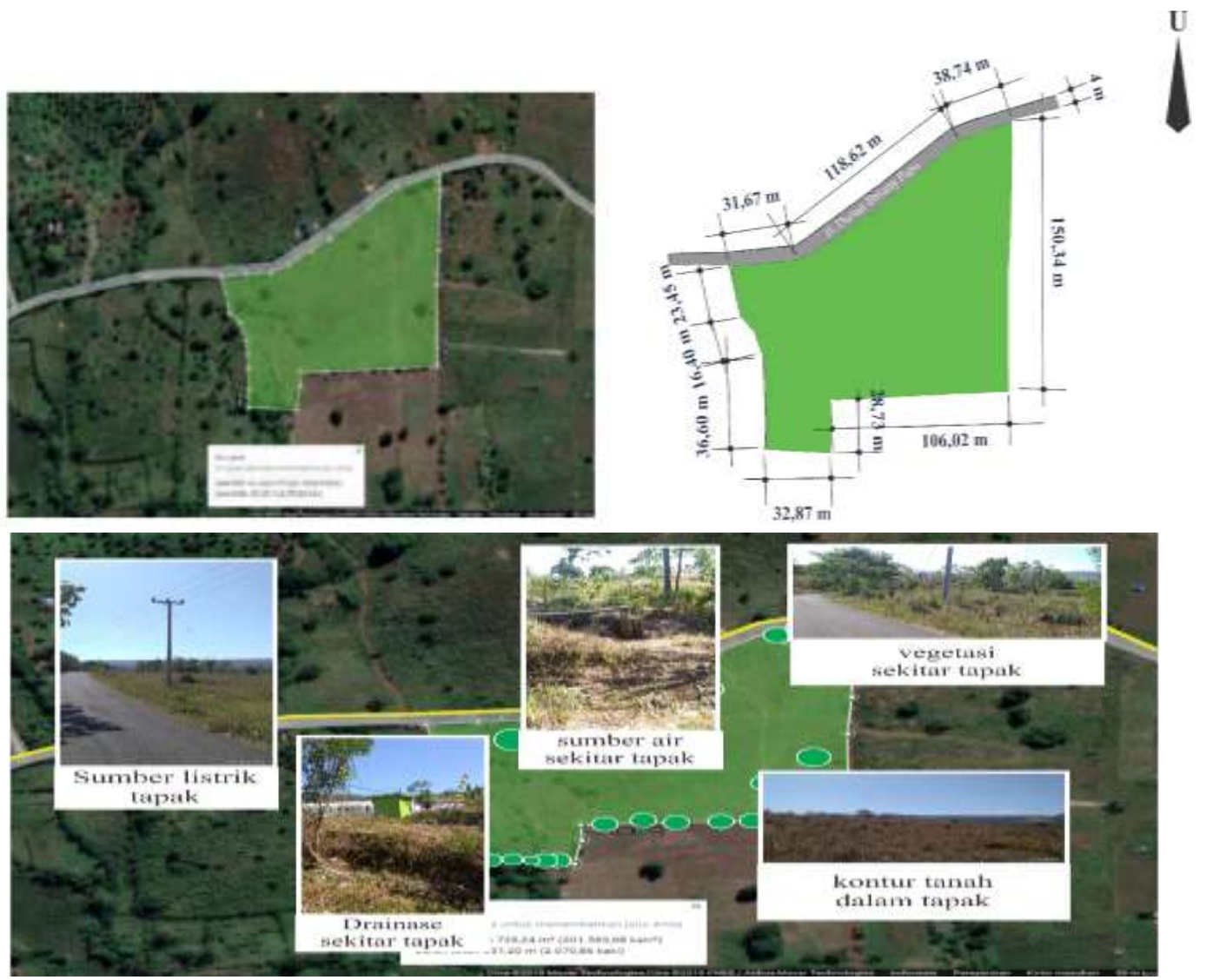

Gambar 2. Kondisi Eksisting Tapak Sumber: Olah Data, 2019

Luas tapak yang terpilih adalah $18.728 \mathrm{~m}^{2}$. Tapak memiliki bentuk yang tidak simetris disemua sisinya. Sisi terpanjang berada di sisi Timur tapak dan beberapa sisi lain memiliki ukuran yang beragam. Orientasi tapak berdasarkan letak jalan berada pada sisi Utara tapak.

\section{Analisis Zonasi dan View}

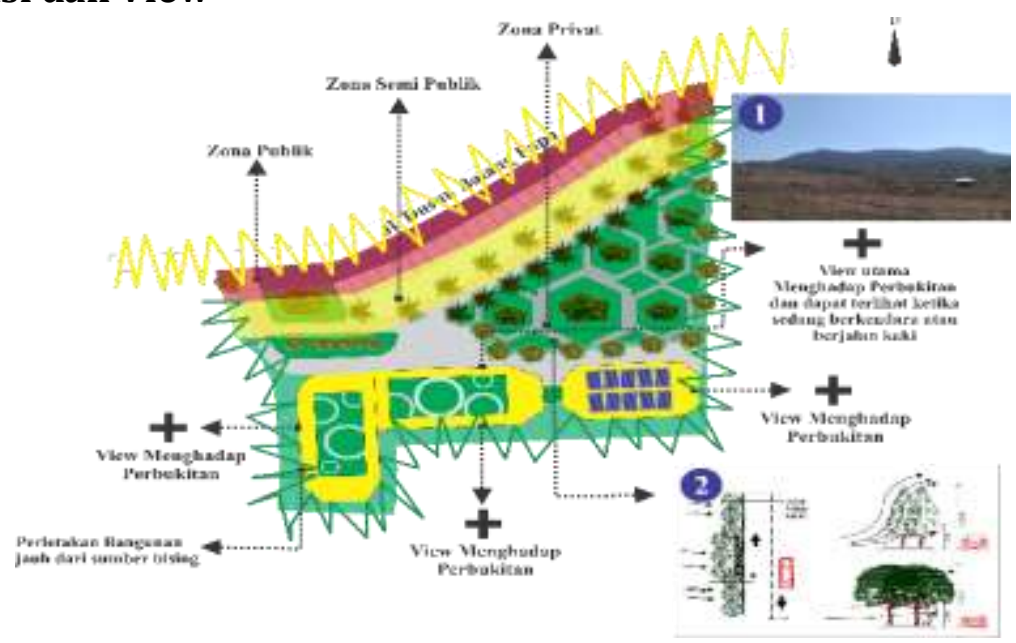

Gambar 3. Analisis Zonasi dan View Sumber: Olah Data, 2019

Zona publik berada di sekitar jalur GSB dan parkir, Zona semi publik mengikuti alur zona publik, Zona privat berada di daerah yang jauh dari zona publik, View utama ke segala 
arah namun direkomendasikan ke arah utara depan tapak. Memanfaatkan vegetasi sebagai penampis sumber bising. Menempatkan bangunan jauh dari sumber bising.

\section{Lintasan Matahari}

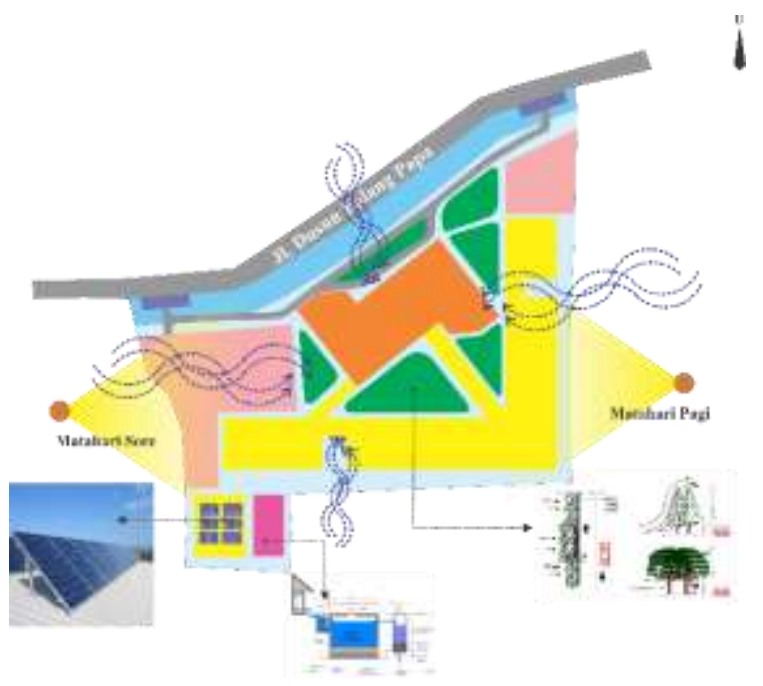

Gambar 4. Analisis Lintasan Matahari dan Klimatologi Sumber: (Olah Data, 2019)

Perletakan bangunan utama menghadap ke arah barat dan utara dengan intensitas matahari yang cukup. Pada tanggapan penghawaan alami bangunan akan dibuatkan celahcelah sebagai sirkulasi utama tapak dan sebagai pengontrol angin yang terlalu kuat. Bangunan penunjang diletakkan menghadap utara. Memanfaatkan sel surya sebagai pembangkit tenaga listrik cadangan di dalam bangunan. Menampung air hujan yang berasal dari atap bangunan ke reservoir.

\section{Zoning Ruang}

Desain awal tapak kemudian dieksplorasi dalam bentuk gambar yang kemudian dituangkan dalam desain. Transformasi pengolahan tapak berdasarkan pertimbangan sirkulasi dan fungsi bangunan yang berhubungan terhadap setiap ruang sebagai berikut:

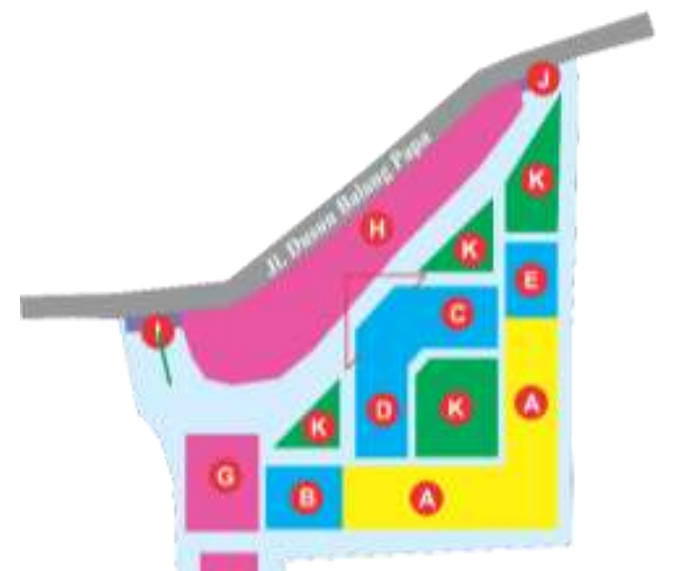

Keterangan:

A. Bangunan Utama

B. UGD dan ICCU

C. Administrasi

D. Poliklinik

E. Kamar Mayat

F. Servis

G. Plumbing

H. Parkir

I. Parkir Khusus Ambulance

J. Jalur Masuk

K. Jalur Keluar

L. Taman dan Plaza 
Penempatan ruang IGD (Instalasi Gawat Darurat) dan ICU (Intensive Care Unit) diletakkan pada bangunan administrasi, namun pada transformasi diubah ke posisi D agar tidak mengganggu sirkulasi pasien gawat darurat dengan pengunjung serta kebisingan. Posisi Ruang poli klinik awalnya didekatkan dengan dengan bangunan utama untuk memudahkan akses dan pengawasan, namun setelah ditransformasikan, bangunan poli klinik disatukan dengan bangunan fungsinya sebagai bangunan penunjang dan berada di zona semi privat. Posisi tandon air awalnya dipisah dengan bangunan servis, setelah ditransformasi kemudian digabungkan untuk mengifisienkan ruang yang tersedia beserta sirkulasi yang lebih mudah. Posisi Parkir pengelola awalnya dianggap jauh dari bangunan administrasi dan pengeloalaan, setelah transformasi berubah posisi ke $G$ agar jangkauan ke bagian administrasi dan penanganan pasien. Parkir pengunjung semula dipusatkan di area jalur masuk bangunan namun dianggap sirkulasi sulit dan kemanan tidak dapat dikontrol. Setelah ditransformasikan berubah ke posisi $\mathrm{H}$ untuk memudahkan sirkulasi dan dipusatkan pada satu area khusus parkir yang tidak mengganggu lalu lintas. Posisi awal taman dan plaza berada di area yang tidak aman dan jauh dari jangkauan pasien. Setelah ditransformasi berubah ke posisi K yang dekat dengan bangunan rehabilitasi untuk memudahkan pengguna dan lebih jauh dari pusat sirkulasi.

\section{B. Konsep Bentuk dan Lay Out Ruang}

Pengolahan bentuk digunakan dalam mengatur posisi dan efisiensi ruangan yang akan terbentuk di dalamnya. Berikut ini hasil transformasi bentuk bangunan Sanatorium.

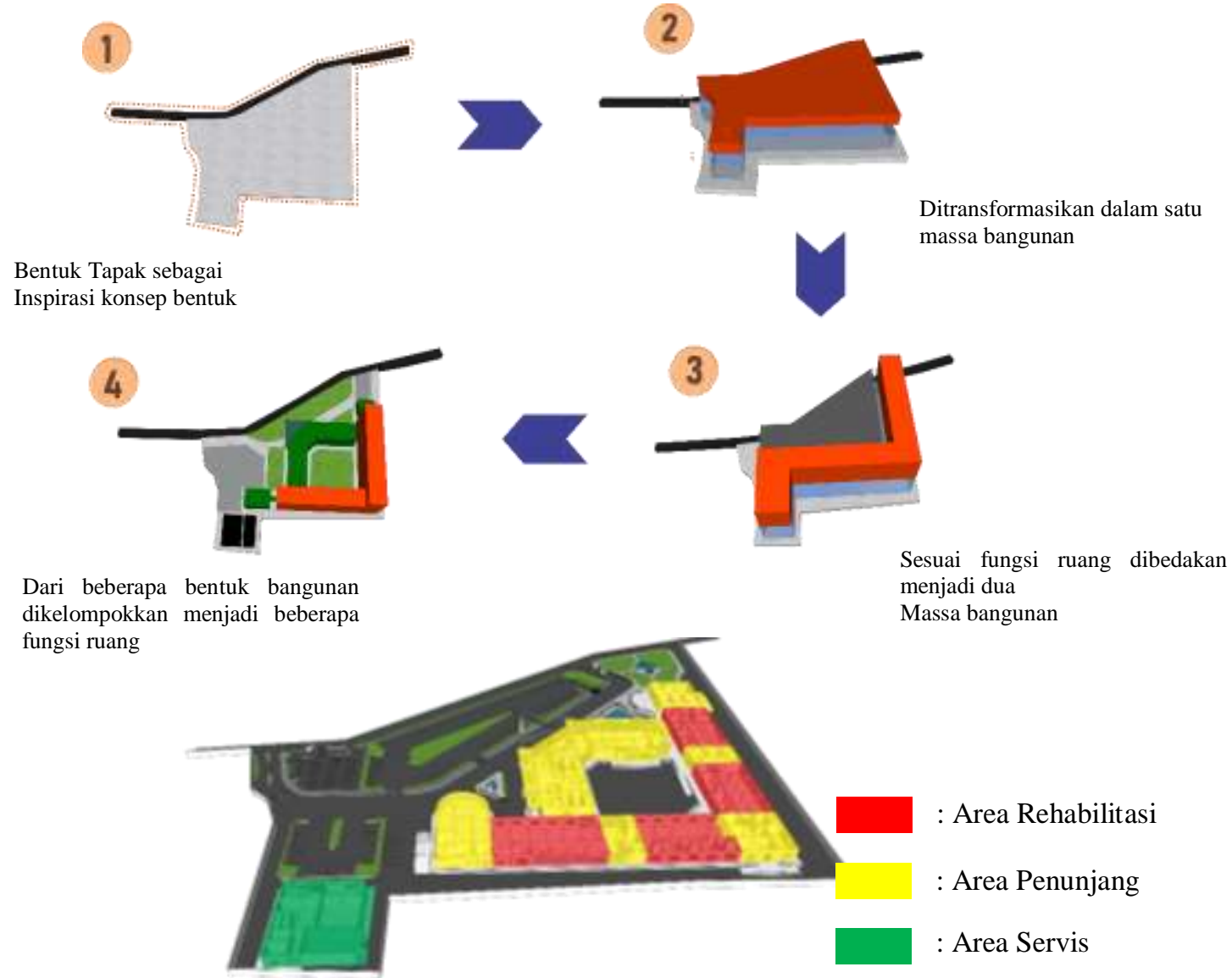

Gambar 6. Konsep Bentuk dan lay Out Zoning Bangunan Sanatorium Sumber: Hasil Desain, 2020 
Bentuk awal bangunan utama memiliki 1 elevasi yang jelas dengan peruntukan sebagai area berjemur, namun dianggap tidak adil untuk pasien karena hanya satu sisi dan tidak simetris. Setelah ditransformasikan menjadi simetris dan elevasi yang seimbang di semua sisi bangunan. Bangunan penunjang dalam hal ini poliklinik dan UGD awalnya berbentuk kaku dan pasis. Setelah ditransformasikan dan ditambahkan bentuk setengah lingkaran agar lebih dinamis dan tidak kaku. Bentuk bangunan servis lebih kaku dan kokoh sesuai fungsinya. Setelah ditransformasi kedua bangunan awalnya terpisah dan untuk mengefisienkan ruang dan lahan, maka digabungkan menjadi satu.

\section{Konsep Penghawaan Alami}

Pendekatan arsitektur berkelanjutan dalam perancangan sanatorium berkaitan dengan sistem penghawaan alami yang ada dalam bangunan. Hal ini selaras dengan pasien TBC yang tidak dapat terpapar langsung dengan pendingin udara (air conditioner) sehingga pada pengaplikasian bangunan menggunakan penghawaan pasif. Berikut ini model penghawaan alami untuk setiap unit.

Tabel 3. Analisis Konsep Penghawaan alami Berdasarkan SNI 2001 pada Desain Sanatorium

Konsep Penghawaan Alami

Kriteria

Penempatan

\section{Penghawaan Alami}

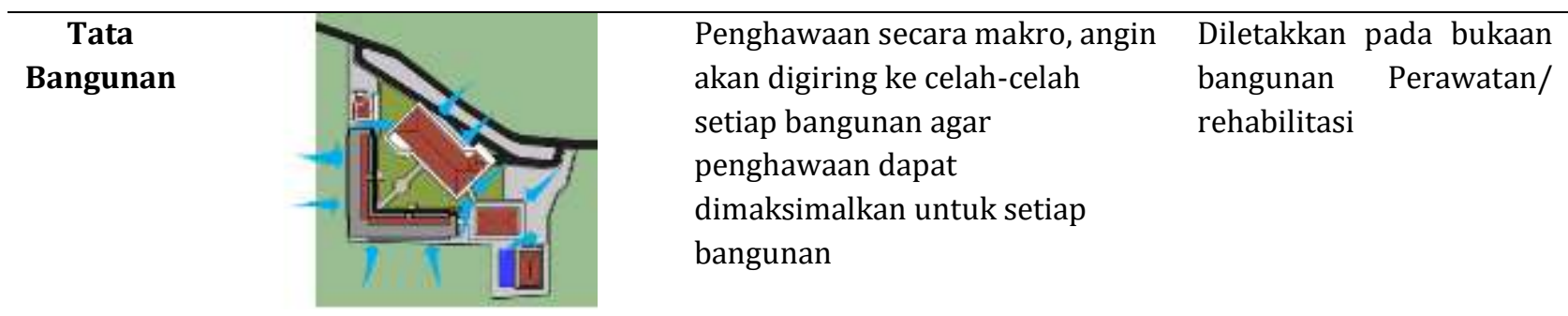

Orientasi $\begin{aligned} & \text { Orientasi bangunan utama } \\ & \text { mengkuti arah angin untuk } \\ & \text { memaksimalkan penghawaan } \\ & \text { dalam ruangan }\end{aligned}$

\begin{tabular}{c}
$\begin{array}{c}\text { Sistem } \\
\text { Cross } \\
\text { ventilasi }\end{array}$ \\
\hline Letak \\
bukaan
\end{tabular}


Konsep Penghawaan Alami

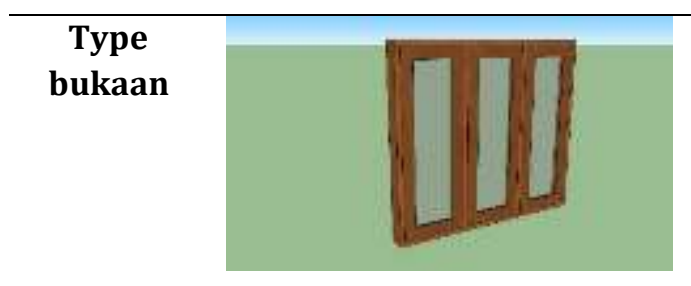

\section{Kriteria}

Ketika semua jendela dibuka dapat memaksimalkan udara yang masuk ke dalam ruangan Mengontrol keluar masuknya udara ke dalam bangunan. Ukuran jendela $1 / 6-1 / 5 \mathrm{X}$ luasan ruang Luas Penerangan tidak termasuk dalam luas penghawaan bangunan.

Menggunakan penghawaan 2 layer dengan kaca yang terpisah. Diletakkan di atas jendela utama dengan tujuan mendistribusi udara yang masuk ke dalam bangunan Luas lubang ventilasi $40 / 1-$ 10/1 X luas ruang

Sumber: Hasil Desain, 2020

Berdasarkan tabel di atas, sistem penghawaan bangunan yang alami berdasarkan penjelasan pada tabel diatas dapat selaras dengan tujuan untuk memudahkan penyembuhan pasien yang menjalani rehabilitasi penyakit, terutama TBC. Namun hal yang penting untuk diperhatikan adalah sistem kontrol pada penghawaan alami yang sulit dikendalikan namun dapat diantispasi menggunakan material lain, misalnya penggunaan gorden pada ventilasi di atas pintu dan jendela.

\section{Hasil Desain}

Bentuk bangunan yang ramping dan terdapat void untuk sirkulasi udara antar massa bangunan. Perletakan bukaan jendela digunakan hamper selur bangunan perawatan / rehabilitasi.

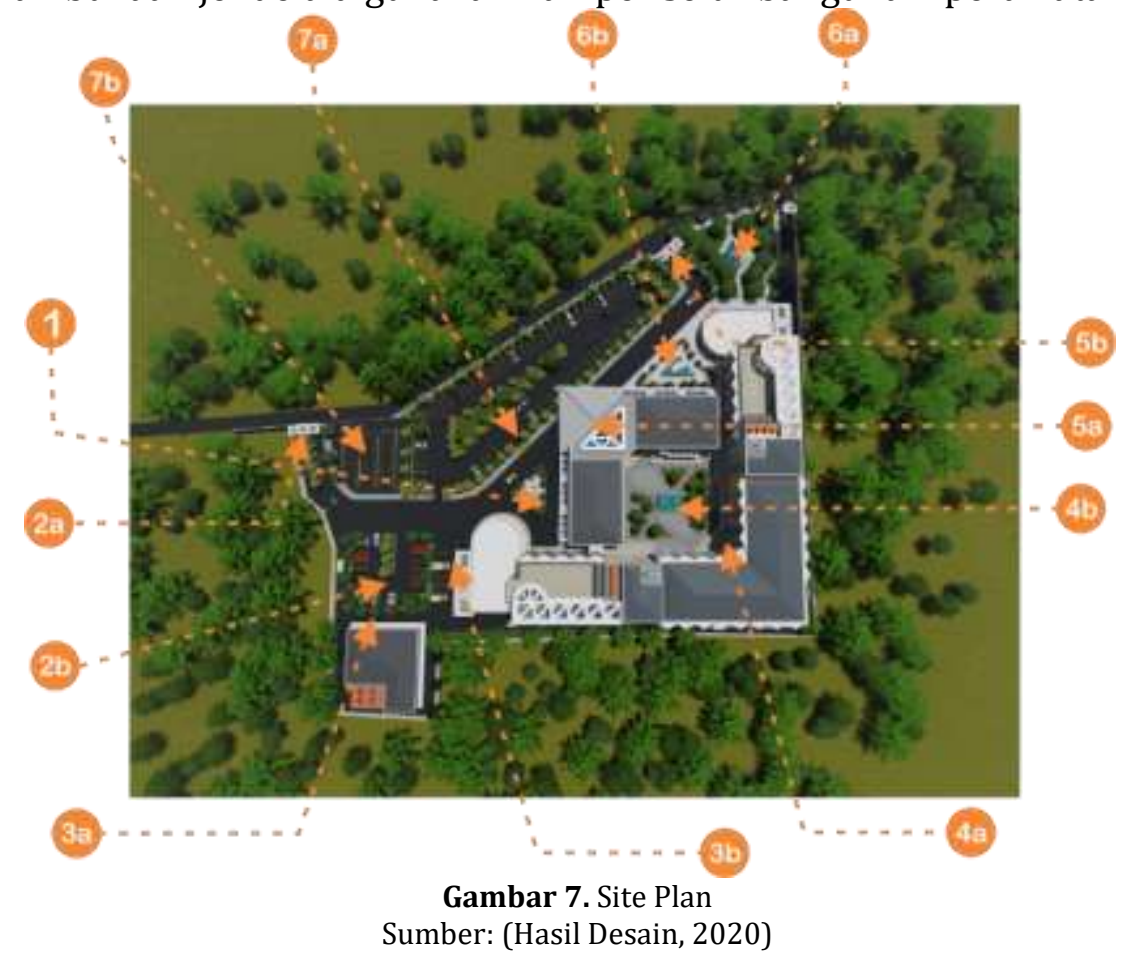


Tabel 3. Keterangan Gambar Site Plan

\begin{tabular}{|c|c|c|}
\hline No. & Kode Gambar & Keterangan \\
\hline 1. & 1 & Bangunan Penerimaan \\
\hline 2. & $2 \mathrm{a}$ & Gerbang Masuk \\
\hline 3. & $2 b$ & Parkir Pengelola \\
\hline 4. & $3 a$ & Daerah Servis \\
\hline 5. & $3 \mathrm{~b}$ & Unit Gawat Darurat \\
\hline 6. & $4 a$ & Bangunan Utama Rehabilitasi \\
\hline 7. & $4 \mathrm{~b}$ & Taman dan Plaza 1 \\
\hline 8. & $5 a$ & Entrance \\
\hline 9. & $5 b$ & Gerbang Keluar \\
\hline 10. & $6 a$ & Taman dan Plaza 2 \\
\hline 11. & $6 \mathrm{~b}$ & Taman dan Plaza 3 \\
\hline 12. & $7 a$ & Parkir Mobil \\
\hline 13. & $7 \mathrm{~b}$ & Parkir Motor \\
\hline
\end{tabular}

Hasil desain perancangan sanatorium dengan penerapan penghawaan alami di Kabupaten Gowa ini diharapkan dapat mewadahi tata laksana penanganan penyakit TBC secara optimal dengan beberapa fasilitas yang ditawarkan di dalamnya. Dukungan letak geografis dan keadaan iklim setempat dan iklim di Indonesia secara umum menjadi faktor-faktor yang penting dalam penanganan penyembuhan pasien meskipun tidak secara langsung.

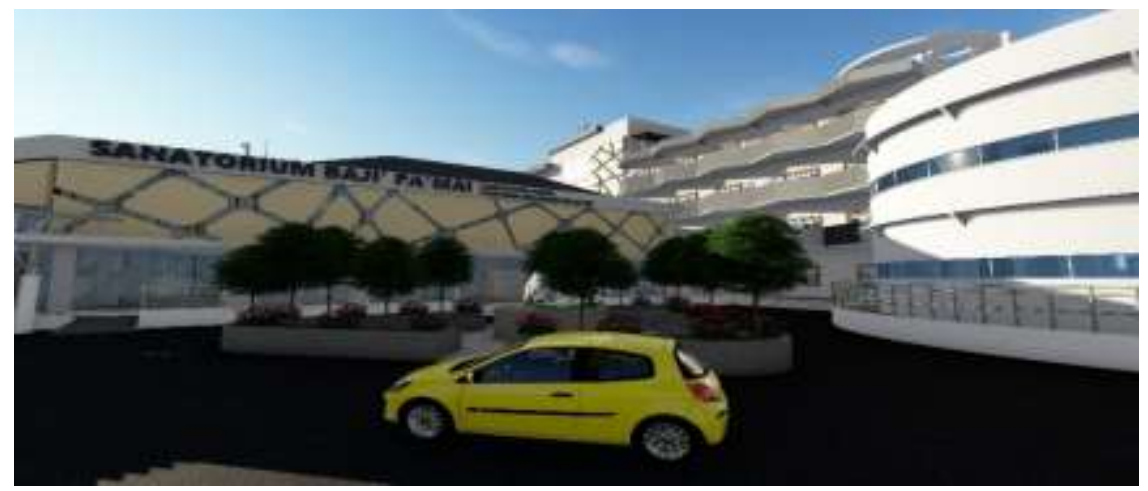

(a) Persepktif Bangunan

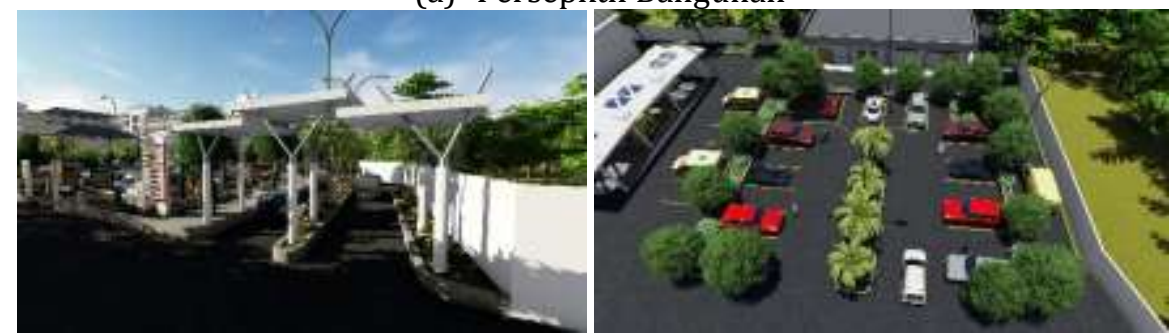

(b) Gerbang Masuk dan Parkir Pengelola

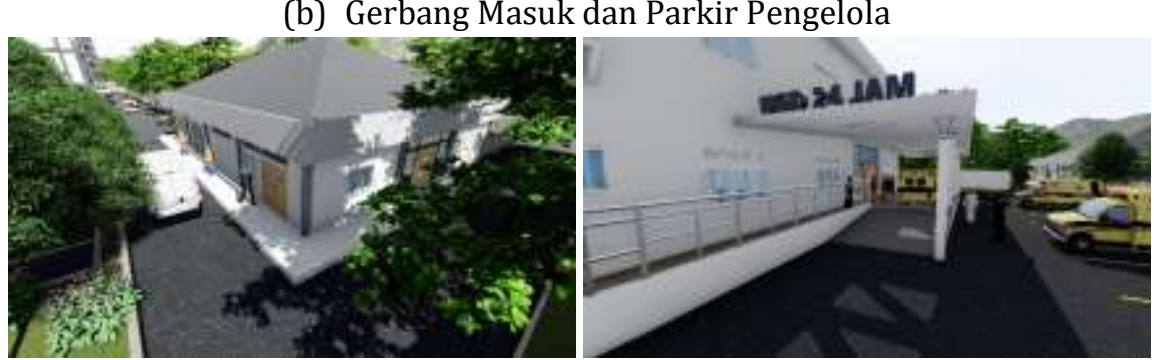

(c) Area Bangunan Servis dan UGD 


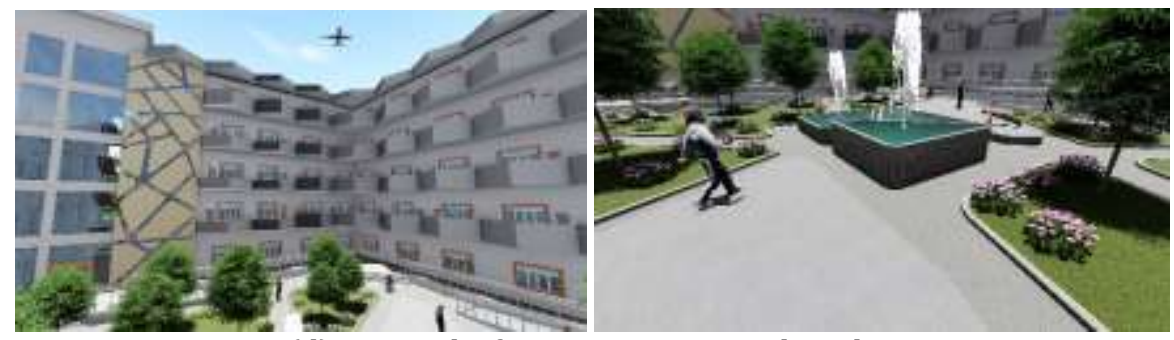

(d) Perspektif Bangunan Utama dan Plaza

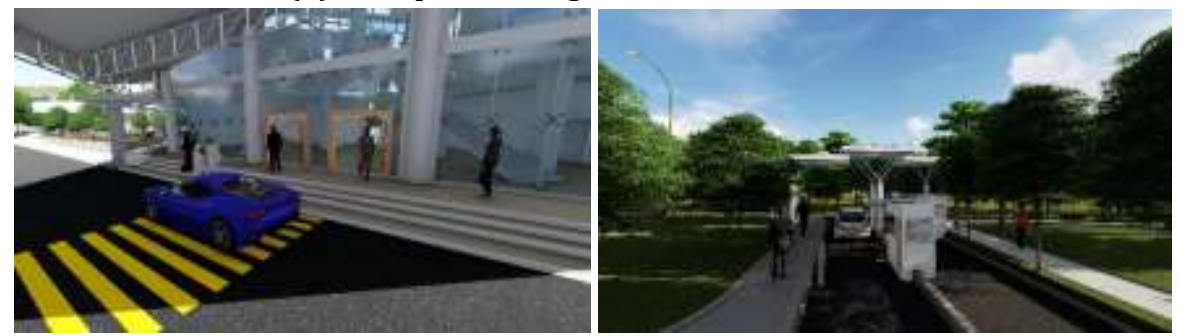

(e) Entrance dan Gerbang Keluar

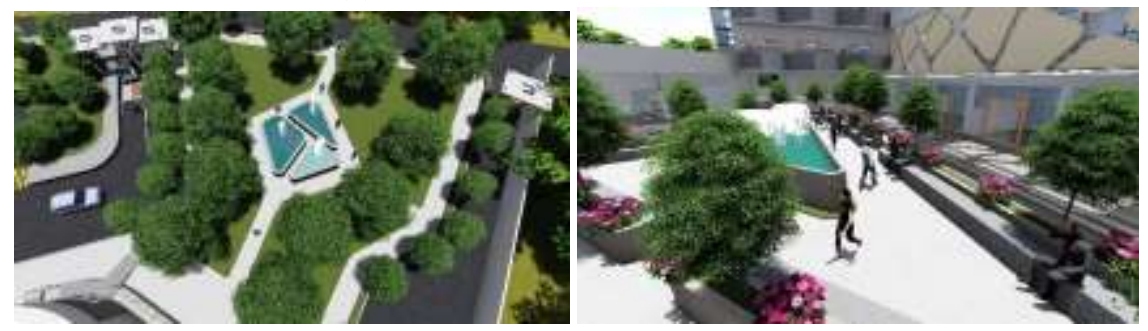

(f) Taman dan Plaza

Gambar 10. (a), (b), (c), (d), (e), (f) Desain Sanatorium Sumber: Hasil Desain, 2020

Ruang-ruang di dalam bangunan disesuaikan dengan kebutuhan pasien serta penambahan sarana-sarana penunjang lainnya sebagai alternatif selain penyembuhan secara medis. Selain itu pada pengaplikasian bangunan dengan konsep penghawaan alami berupa konsep jendela sebagai sirkulasi udara utama ditambah dengan ventilasi sebagai pengontrol udara. Hal ini dapat mengurangi konsumsi energi yang berlebih terutama dalam penggunaan penghawaan buatan. Dengan demikian, sanatorium bukan hanya sebagai wadah penyembuhan pasien namun sebagai bentuk pelestarian penghematan energi secara komprehensif (tabel 3).

\section{KESIMPULAN}

Berdasarkan pembahasan dapat diperoleh simpulan berupa wujud penggunaan konsep penghawaan alami berupa lokasi bangunan yang berada pada suhu nyaman dan sirkulasi udara yang masih alami, tata bangunan dengan konsep void, bentuk bangunan yang ramping / tidak melebar, letak bukaan jendela harus sesuai arah angin penghawaan . Penulis mengakui bahwa masih banyak konsep pengahwaan alami yang bisa dikaji lebih lanjut dan diterapkan pada bangunan masa kini dengan fungsi yang berbeda. Terima Kasih kepada Pemerintah Kota Gowa yang telah banyak membantu penulis dalam hal memperoleh data primer.

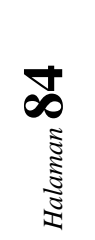




\section{DAFTAR REFERENSI}

Ardiani, Y. Mila. 2015. Sustainable Architecture Arsitektur Berkelanjutan. Edited by Erlangga. Jakarta.

Arifah, A B, and M S Adhitama. 2017. "Pengaruh Bukaan Terhadap Kenyamanan Termal Pada Ruang Hunian Rumah Susun Aparna Surabaya.” Jurnal Mahasiswa Jurusan Arsitektur 5 (4). http://arsitektur.studentjournal.ub.ac.id/index.php/jma/search/advancedResults.

BPS Kabupaten Gowa, 2017.

Budiastuti, H., Mauliani, L., \& Nur'aini, R. D. 2018. "Pengaplikasian Arsitektur Kesehatan Pada Sanatorium Di Gunung Pancar.” Purwarupa Jurnal Arsitektur 2 (1): 45-50.

Kementerian Kesehatan RI. 2018. Peraturan Menteri Kesehatan Republik Indonesia Nomor 4 Tahun 2018.

Kusumawardani, N, and J Thojib. 2015. "Sistem Ventilasi Alami Sebagai Dasar Perancangan Jfc Center Di Kabupaten Jember." Jurnal Mahasiswa Jurusan Arsitektur. http://arsitektur.studentjournal.ub.ac.id/index.php/jma/article/view/75.

SNI. 2001. SNI 03-6572-2001 : Tata Cara Perancangan Sistem Ventilasi Dan Pengkondisian Udara Pada Bangunan Gedung. Jakarta.

Tribun Timur. 2016. "Kualitas Udara Kabupaten Gowa Membaik.” Tribunnews. Com., 2016.

Utomo, Y, and W Iyati. 2019. "Rekayasa Bukaan Ventilasi Alami Untuk Meningkatkan Kenyamanan Termal Pondok Pesantren Darul Hikam Di Mojokerto.” Jurnal Mahasiswa Jurusan Arsitektur. http://arsitektur.studentjournal.ub.ac.id/index.php/jma/article/view/764.

Warren, Peter. 2016. "The Evolution of the Sanatorium: The First Half-Century, 1854-1904." Canadian Bulletin of Medical History. https://doi.org/10.3138/cbmh.23.2.457. 